HEIDER, F. The psychology of interpersonal relations. New York: WiFey, 1958.

MILLER, D. C. Handbook of research design and social measurement. New York: David McKay, 1964.

PIAGET, J. The moral judgment of the child. New York: Harcourt-Brace, 1932.

SHAW, M. E., BRISCOE, M. E., \& GARCIA-ESTEVE, J. A cross-cultural study of attribution of responsibility. International Journal of Psychology, 1968, 3, 51-60.

SHAW, M. E., \& SCHNEIDER, F. W. Social class differences in attribution of responsibility and sanctioning behavior. Research Report No. 5 NSF Grant GS-647, University of Florida, 1967

SHAW, M. E., \& SCHNEIDER, F. W. Intellectua competence as a variable in attribution of responsibility and assignment of sanctions. Journal of Social Psychology, in press.
SHAW, M. E., \& SULZER, J. L. An empirical test of Heider's levels in attribution of responsibility. Journal of Abnormal \& Social Psychology, 1964, 69, 39-46.

SULZER, J. L. Attribution of responsibility as function of the structure, quality, and intensity of the event. Unpublished doctoral dissertation University of Florida, 1964.

\section{NOTES}

1. This research was supported by NSF Grant GS-647. The statistical analyses were done by the University of Florida Computing Center.

2. Sulzer, J. L., \& Shaw, M. E. A comparison of pattems of responsibility attribution in Negroes and whites. Unpublished research, University of Florida, 1964.

3. Readers interested in obtaining a copy of the complete statistical analy ses may write to the first author.

\title{
The effects of an irrelevant stimulus variable on transposition
}

\author{
NANCY WRAY DAHLEM, Saint Louis \\ University, St. Louis, Mo. 63103
}

On an intermediate size problem, either white cubes were used on both training and test trials, or irrelevant color cues were introduced at the outset of test trials. Analysis of the first test trial data indicated no effect of color on the frequency of transposition responding. Analysis of total test data (18 trials) indicated that color, as a within-trials variable, interfered with transposition.

It has been suggested that the degree of difference among test stimuli and "noticeability" of the change between training and test stimuli are determinants of transposition (Reese, 1968; Zeiler, 1967). Yet, studies concerned with differences within stimulus sets have manipulated only cues on the stimulus dimension relevant to problem solution. Also, only four studies known to the writer have attempted to influence the probability of noticing the change from training to test stimuli by manipulating cues on an irrelevant stimulus dimension. Of these latter studies, one is difficult to interpret because type of cue manipulation used was confounded with the distance of the test (Shirai, 1954). A second offers little general information because retardates were on a partial reinforcement schedule during the training task (Thompson, 1965). Of the two remaining studies, one offers clear support for the idea that failure to notice a training-test difference is crucial for transposition (Stevenson, Langford, \& Reese, 1955) whereas the other offers only questionable support for the idea (Hansen \& Cole, 1968).

The present study investigated the frequency of transposition responses on an intermediate size problem when irrelevant color cues were introduced as one-step (near test) and three-step (far test) trials began. Colors were introduced to test the ideas that degree of difference among test stimuli and "noticeability" of the change from training to test stimuli are factors important to transposition.

\section{METHOD}

The Ss were 150 kindergarteners. ${ }^{2}$ They were randomly assigned to the six conditions of the experiment with the restriction that each condition include an equal number of Ss.

Materials were a 12-in.-high screen which shielded E's hand movements from S's view, a felt-covered stimulus presentation tray, and a series of wooden cubes. The white, red, blue, and yellow cubes measured 1 to $2 \frac{1}{4}$ in. on a side, with cubes adjacent in the series differing from one another by $1 / 4$ in. on a side.

Triads of cubes were presented simultaneously on the stimulus tray via a trapdoor under the screen which separated the $E$ from the $S$. Midpoints of the cubes were aligned with a 2-in. inter-cube separation. Spatial position of the cubes was randomized over trials so that each size cube occupied the left, middle, and right spatial positions twice during each block of six trials. Responses to the middle-sized cube were consistently reinforced by "finding the hole" drilled in the bottom of the middle-sized cube and by E's verbal "good" or "fine."

During training, all Ss were presented with white $1-, 1 \frac{1}{4}-$, and $1 \frac{1}{2}$-in. cubes for 75 trials or until a criterion of five of six correct responses was met. No $S$ failed to reach the criterion within the 75-trial limit.

On reaching the criterion on the training task, Ss were switched, without comment, to the near test (stimuli $=1 \frac{1}{4}, 11 \frac{1}{2}$, and $13 / 4$ in.) or to the far test (stimuli $=13 / 4,2$, and $2 \frac{1}{4}$ in.). Subjects in the control (C) condition continued to work with white cubes, as those in the between-trials (B-T) condition and the within-trials (W-T) condition began working with red, blue, and yellow cubes. Response to the middle-sized cube was reinforced on all 18 test trials.

For $S s$ in the B-T condition, all three cubes used on a trial were the same color. The color of cubes changed from trial to trial so that, in each block of six trials, cubes were red on two trials, blue on two trials, and yellow on two trials. The aim of this manipulation was to make the change from training to test stimuli more noticeable than it was in the $\mathrm{C}$ condition.

Subjects in the W-T condition were exposed to one red, one blue, and one yellow cube on each trial. Each color was paired with each size cube on two trials during each block of six trials (e.g., for all W-T Ss, the middle-sized block was yellow on Trials 1 and 5 , blue on Trials 2 and 4 , and yellow on Trials 3 and 6 on the first block of trials). The aim of this manipulation was to make the change from training to test stimuli more noticeable than in the $C$ condition and to accent the difference among test stimuli.

\section{RESULTS}

Trials to criterion on the training task were analyzed by a 3 (conditions) by 2 (distance) analysis of variance. All of the Fs were $<1$.

The test trials data were analyzed by use of chi square tests and two analyses of variance. The dependent variables were: number of first-trial transposition responses, number of transposition responses during the first six trials, and number of transposition responses over three blocks of six trials each.

The first-trial data shown in Fig. 1 indicated that the frequencies of transposition responses in the B-T and the W-T conditions were identical or nearly

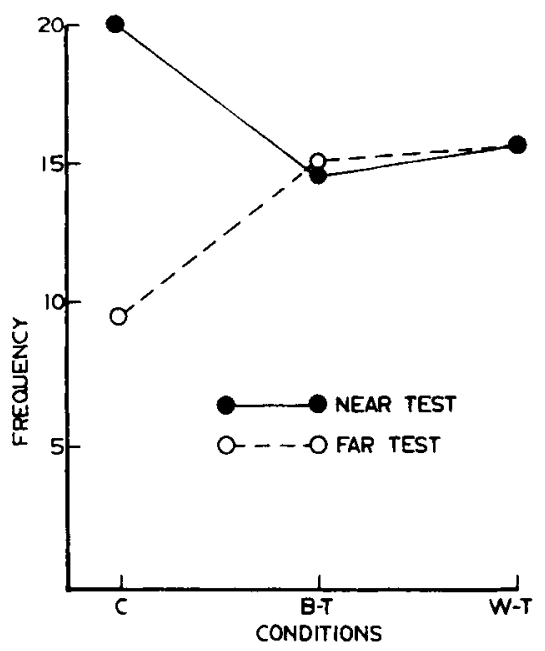

Fig. 1. Transposition responses on the first test trial. 
identical regardless of the distance of the test. In contrast, the difference between frequency of transposition responses in the near- and far-test $C$ conditions was sizable. $A$ chi square test verified that the distance effect in $C$ condition was significant at beyond the .005 level $\left(\chi^{2}=8.210, \mathrm{df}=1\right)$. Comparisons among frequencies of transposition responses given by near-test $S s$ ( $C$ vs B-T vs W-T) and among far-test $\mathrm{Ss}$ (C vs B-T vs W-T) yielded nonsignificant chi squares (near test $\chi^{2}=3.087, \mathrm{df}=1$; far test $\left.\chi^{2}=3.851, \quad \mathrm{df}=2\right)$. Apparently the disappearance of the distance effect with the introduction of color cues was the result of a nonsignificant trend toward inhibition of transposition for near-test $\mathrm{Ss}$ and a nonsignificant facilitation of transposition responses for far-test $\mathrm{Ss}$.

A 3 (conditions) by 2 (distance) analysis of variance of the data from the first six test trials indicated a significant distance effect within these early test trials (near test $\bar{X}=4.693 ;$ far test $\bar{X}=3.173 ; \mathrm{p}<.005)$. No other Fs were significant at the .05 level. Failure to find a significant conditions by distance effect during these first six test trials indicated that the trends noted in the first-trial data did not persist, even over these few test trials.

A 3 (conditions) by 2 (distance) by 3 (blocks) mixed analysis of variance indicated that the between-Ss effects of conditions $(F=5.981 ; \quad d f=2 / 144$; $\mathrm{p}<.005)$ and distance $(\mathrm{F}=16.652$; $\mathrm{df}=1 / 144 ; \mathrm{p}<.005$ ) were significant, as were the within-Ss effects of blocks $(F=63.713 ; \mathrm{df}=2 / 288 ; \mathrm{p}<.005)$ and the distance by blocks $(F=11.109, \mathrm{df}=2 / 288$; $\mathrm{p}<.005$ ). Since relatively large Ns were involved in all comparisons, it was decided to avoid the accumulation of alpha error by use of Scheffe's test where analyses subsequent to the analysis of variance were needed (Petrinovich \& Hardyck, 1969).

Results indicated that the mean number of transposition responses was greater in the near test $(\bar{X}=15.293)$ than in the far test $(\bar{X}=12.493)$. Also, Condition $B-T$ yielded fewer transposition responses $(\bar{X}=12.340)$ than the $C_{-}(\bar{X}=15.200)$ or the W-T conditions $(\bar{X}=14.120)$. These last two conditions did not differ from one another significantly. There was an overall increase in mean number of transposition responses over blocks of trials, but the increase on the near test occurred only between Blocks 1 and 2, whereas differences between Blocks 1 and 2 and Blocks 2 and 3 were both significant on the far test (near test $\overline{\mathrm{X}} \mathrm{s}=4.693,5.200$, and $5.400 ;$ far test $\bar{X}_{s}=3.173,4.440$, and 4.880 ). On all trial blocks, significantly more transposition responses occurred on the near test than on the far test. These differences occurred despite the fact that only $73 \%$ of near-test Ss and $63 \%$ of far-test Ss were making transposition responses consistently throughout the last block of trials.

\section{DISCUSSION}

One effect in the data worthy of mention is that the first-trial data and the totaltrials data are not entirely consistent in the conclusions they suggest. The firsttrial data suggest that a distance effect is limited to the $C$ condition, whereas the total-trials data indicate no Conditions by Distance interaction. In addition, the first-trial data suggest that the introduction of color cues, regardless of whether they are likely to influence only the probability of noticing the change from training to test stimuli or whether they are also likely to exaggerate differences among test stimuli, have no significant effect upon the frequency of transposition responses. In contrast, the total-trials data suggest that making it more probable that Ss will notice the change from training to test stimuli is not important under the conditions of this experiment, but that exaggerating differences among test stimuli is an important determinant of the frequency of transposition responding.

The present finding of no significant effect of introducing color cues as a between-trials variable is consistent with the Hansen \& Cole (1968) finding of no effect of stimuli color change when comparisons were made among test-trial data. It is inconsistent with the Stevenson et al (1955) finding that nursery-school children gave fewer transposition responses when a color change was introduced at the outset of test trials on a two-choice discrimination problem.

The notion that increasing the probability of noticing the change from training to test stimuli would result in few transposition responses gains little support from this data. When color was introduced, at least $56 \%$ of Ss in each experimental group made a transposition response on the first test trial. The fact that there was no Conditions by Blocks interaction in the total-trials data also works against this notion when it is recalled that during test trials responses to the middle-sized stimulus were consistently reinforced. That introduction of color as a between-trials variable resulted in a trend toward more transposition for far-test $S s$ is also hard to explain when failure to notice the training-test change is considered to be a variable critical to transposition responding.

Although it might be argued that what appears to be an effect of exaggerating the differences among test stimuli (W-T conditions) in the total test data may be reflecting nothing more than a preferential color bias that outweighs the effect of reinforcement, several findings argue against this interpretation. First, the data indicate that only five (10\%) of Ss failed to respond to each of the three colors on at least one trial in the first block of six trials. Second, only two near-test Ss and four far-test Ss responded most frequently to the same color cue in Blocks 1 and 2. Only two far-test Ss showed a consistent color preference on all three trial blocks. Finally, if a strong preference for a particular color cue were operating, one would have expected a significant Conditions effect in the analysis of the first six test trials and/or a significant Conditions by Blocks in teraction in the total test data. Neither of these effects was significant at even the .05 level.

In summary, the analyses of the first trial data and the total test data are consistent in suggesting that failure to notice the difference between training and test stimuli is not a factor critical to transposition responding. The two analyses are not in agreement regarding the effects of exaggerating the differences among test stimuli since only the total trials data suggest that this manipulation has a detrimental effect on transposition.

\section{REFERENCES}

HANSEN, B., \& COLE, M. Discriminability and transposition on the intermediate size problem. Journal of Experimental Child Psychology, 1968,6, 174-180.

PETRINOVICH, L. F., \& HARDYCK, D. D. Error rates for multiple comparison methods: Some evidence concerning the frequency of erroneous conclusions. Psychological Bulletin, 1969, 71, 43-54.

REESE, H. W. The perception of stimulus relations. New York: Academic Press, 1968.

SHIRAI, T. Relationship between type of visual discrimination of size and accuracy of memory of size. Unpublished doctoral dissertation University of Toronto, 1954.

STEVENSON, H. W., LANGFORD, T., \& REESE, H. Transposition in preverbal children American Psychologist, 1955, 10, 406.

THOMPSON, G. R. Effects of number of relevant stimulus dimensions and kind of verbal pretraining on transposition in retardates. Unpublished doctoral dissertation, University of Minnesota, 1965.

ZEILER, M. D. Stimulus definition and choice. In L. P. Lipsitt and C. C. Spiker (Eds.), Advances in child development. Vol. 3. New York: Academic Press, 1967.

\section{NOTES}

1. The author wishes to express appreciation to Kathleen Fitzgerald for collecting the data reported here.

2. The author wishes to express her appreciation to the Superintendent of Schools, Clayton, Missouri, and to the principals and teachers who provided the $S s$ and the space required for execution of this study. 